Specific proposals about how this might be achieved using either Fermilab's Tevatron or Brookhaven's Isabelle have been drawn up at Columbia University under the enthusiastic guidance of $\mathrm{Dr}$ Robert Wilson, ex-director of Fermilab.

According to Dr Wilson, the physics possibilities, which include the study of interactions with polarised electron beams, are 'substantial'. He also argues that an electron-proton collider is "competitive with more expensive projects" - a crack at the SLAC proposal which is likely to cost two or three times the $\$ 30$ million he says the electron-proton project needs for "a modest experiment at low energy".

Fermilab scientists, initially sceptical about the practicality of adding an intersecting electron ring, have carried out their own calculations and found the technical aspects relatively straightforward.

Scientists at Columbia are enthusiastic about the idea. They suggest that although considerable uncertainty exists about what might be found, electron-proton interactions could help elucidate the structure of quarks. They might even, according to Dr W Lee, provide under certain conditions a quark 'factory'.

Enthusiasm for such a project has also come from Canada, where physicists have independently been working on their own proposal to add an electron ring at Fermilab.

A steering committee has been set up for what is known as the Canadian High Energy Electron Ring (CHEER), and it is intended to present a feasibility study for a project costing about $\$ 50$ million to the Canadian government in September.

There could even be scope for Japanese participation. Japan already has provisional plans for its own electron-proton machine. But this would not be built for some time; and meanwhile some physicists are arguing that there is scope for a multilateral project drawing on the resources of all three nations.

Physicists less directly involved are more ambivalent about the proposal. They accept the argument that if Stanford's experiment only precedes the broaderbased European experiments by a year or two, there may be little advantage in duplicating efforts. However, many feel that recent advances in high energy physics indicate that electron-positron scattering could prove a more fruitsul direction that stabbing in the dark with electron-proton collisions.

The picture is further clouded by the informally-announced intentions of Cornell University to develop a rival proposal to SLAC for raising the energy of its electron storage ring (CESR) to the range where the $Z^{0}$ particle is expected to be found. So, if funds for a new construction somehow materialise in next year's HEP budget - at present a rather faint possibility - intense competition can be expected for the direction in which they will be allocated.

0028-0836/80/200123-02\$01.00 (c) 1980 Macmillan Journals Ltd

\title{
Academy to examine US links with European and Japanese scientists
}

FINANCIAL stringencies have reduced the contact of US scientists - particularly those at an early stage of their careers with colleagues in other western countries precisely when these countries are beginning to catch up and occasionally surpass the US in scientific capability. This trend is worrying some US scientists. The National Academy of Sciences is therefore setting up a new committee on international human resource issues to look at the obstacles to closer links between US scientists and their colleagues in western Europe and Japan.

Academy officials say that the need for such a study comes more from a general impression of declining contacts than from any body of hard data. But they point, for example, to a recent NAS study which showed that there was a $55 \%$ drop between 1971 and 1977 in the number of new PhDs in science and engineering - indicating a firm commitment to postdoctoral study abroad.

The numbers involved are not large; in 1971 the total number was 409 , and by 1977 this had fallen to 147 , a decline from $2.4 \%$ to $1.2 \%$ of the total PhDs. But the trend this indicates is confirmed by more anecdotal evidence of the low number of US scientists to be found in most European laboratories, and the decreasing tendency to request foreign travel funds as a component of applications for research grants.

Academy President Dr Philip Handler warned the academy's members at their annual meeting in Washington last month that although small science in Europe seemed to be suffering the same financial pressures as in the US, cooperation in big science was proceeding rapidly, with potential implications for trans-Atlantic scientific relations.

"As their common strategic planning waxes, the strength of their scientific relations with this country will undoubtedly wane unless we exert special efforts," Dr Handler said. "That makes particularly ironic the decline in the number of young American scientists who can arrange meaningful experiences in European laboratories - where the benefits of such experience are now larger than ever."

Dr Handler said that he had asked the academy's foreign secretary, Dr Thomas Malone, to take a closer look at the changing relationships and "to ascertain whether we are losing touch with European science and whether any important trends may be discerned."

The chairman of the new committee is Dr Walter Rosenblith, Provost of the Massachusetts Institute of Technology, and funding for the committee's work is currently being sought from a number of government agencies and private foundations.

If appropriate funds are forthcoming, the committee will initially set up a number of working groups to examine issues such as the funding of foreign travel by US scientists, and the effects of national taxation, employment and immigration policies on scientific exchange. The focus of the committee's work xill be on links with western Europe and Japan, possibly including other western industrialised nations such as Australia, but omitting either the USSR or the Third World.

Dr Rosenblith said last week that a proper study could not be carried out by the US alone, but would benefit from the active participation of other nations, either individually or through organisations such as the European Science Foundation. "It is a question of the general rationalising of resources" Dr Rosenblith said. "We want to be sure that science as an international activity does not become too fragmented."

David Dickson

\section{US signs scientific cooperation agreement with Japan}

PRESIDENT Carter and Japanese Prime Minister Masayoshi Ohira last week signed a five-year agreement covering cooperation in scientific and technological research between the US and Japan.

In addition to encouraging more conventional forms of scientific exchange, the agreement provides a framework for the development of joint research projects between the two countries, and follows an earlier agreement on energy research which was signed in Washington last May.

Officials from both sides have identified 40 projects on which possible collaboration is now being investigated. These include the use of recombinant DNA techniques, particle accelerator research, and studies of the detoxification and disposal of hazardous wastes and the climatic impact of increased carbon dioxide concentrations in the atmosphere.

One area in which plans for bilateral cooperation are already well advanced is in space research, where agreement in principle has already been reached for collaboration on 17 projects, and has formally been signed on nine. Areas of joint collaboration include the study of plasmas close to the Earth, and projects for a possible mission to rendezvous with the Comet Halley, and to send a joint orbiter and probe to Saturn. 